\title{
NEW RECORDS OF CHIRONOMIDAE (DIPTERA) FROM CONTINENTAL FRANCE
}

\author{
Joel Moubayed-Breil \\ Applied ecology, 10 rue des Fenouils, 34070-Montpellier, France, \\ Email:jm.aquabiol@neuf.fr
}

\begin{abstract}
Material recently collected in Continental France has allowed me to generate a list of 83 taxa of chironomids, including 37 new records to the fauna of France. According to published data on the chironomid fauna of France 718 chironomid species are hitherto known from the French territories. The nomenclature and taxonomy of the species listed are based on the last version of the Chironomidae data in Fauna Europaea, on recent revisions of genera and other recent publications relevant to taxonomy and nomenclature.
\end{abstract}

\section{Introduction}

French territories represent almost the largest variety of aquatic ecosystems in Europe with respect to both physiographic and hydrographic aspects. According to literature on the chironomid fauna of France, some regions still are better sampled then others, and the best sampled areas are: The northern and southern parts of the Alps (regions 5a and 5b in figure 1); western, central and eastern parts of the Pyrenees (regions 6, 7, 8), and South-Central France, including inland and coastal rivers (regions 9a and 9b). The remaining regions located in the North, the Middle and the South-East of France have received little attention and are still only partially explored and need to be prospected more in the years to come.

According to published data accumulated since 1991 there are 681 registered species from France (Serra-Tosio and Laville 1991, Laville and SerraTosio 1996, Moubayed et al. 2000, Garcia and Laville 2000, Delettre 2001, Sæther and Spies 2004). In the current paper, I give a complementary checklist of new records on the basis of recent field work throughout Continental France over the last two decades. The habitats sampled include high altitude peat pits, springs and streams, mountain lakes and reservoirs, temporary streams and pools. Fully developed pharates, adults, pupae, pupal exuviae and larvae were sampled from chironomid populations throughout the various geographic regions.

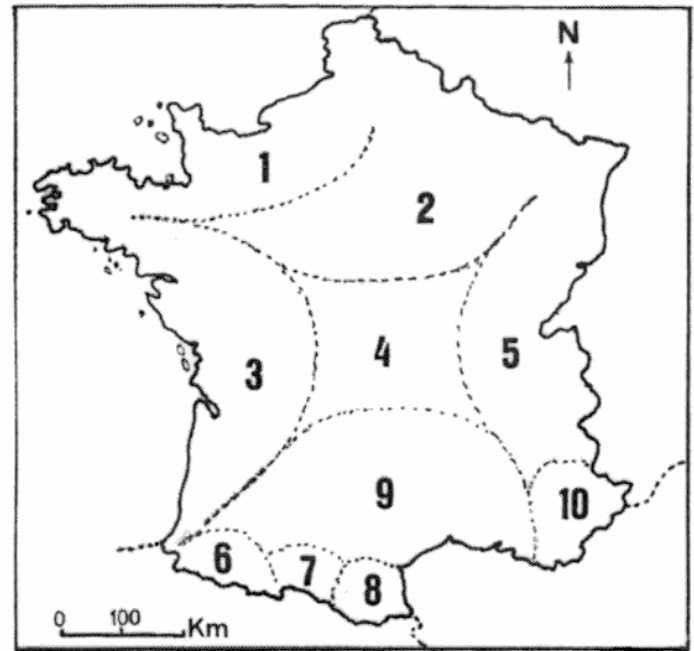

Figure 1. Major biogeographic regions and subregions of France

\section{Sites and methodology}

The identification of slide mounted specimens was aided by recent taxonomic revisions and keys to adults or pupal exuviae (Reiss and Säwedal 1981; Tuiskunen 1986; Serra-Tosio 1989; Sæther 1990; Soponis 1990; Langton 1991; Sæther and Wang 1995; Kyerematen and Sæther 2000; Michiels and Spies 2002; Vårdal et al. 2002; Langton and Visser 2003; Sæther and Spies 2004; Stur and Ekrem 2006; Ekrem 2006; Ekrem 2007) as well as of recent general recommendations on taxonomy and nomenclature (Sæther and Ferrington 2003; Spies and Sæther 2004). Previous geographical distribution of the species was based on the last version of the Chironomidae data in Fauna Europaea (Sæther and Spies 2004), on the latest unpublished data for Fauna Europaea (Sæther and Spies pers comm.), as well as on the taxonomic publications listed above.

The collection sites were located in the ten major physiographic and biogeographic regions and subregions of France (Corsica not included, Figure 1). The habitats sampled include springs, permanent and temporary streams and pools, peat pits, rhithral and potamal of rivers, estuaries, lakes and ponds. An informative map on the biogeographic regions of France is also given by 
Serra-Tosio and Laville (1991). Within the ten prospected regions, two are located in northern France (1 and 2), three in central-south and central France (3, 5 and 4) and five (6, 7, 8, 9 and $10)$ in southern France. The geographic delimitation of the ten regions and subregions is:

- 1, North-West France, including both the Channel and the North Sea coastal streams (1a) and potamic parts of the Seine river basin (1b).

- 2, North-East France, rivers located in the plain and piedmont including the upper stream of the Seine river basin.

- 3, Central-South-West France, including both the Atlantic coastal rivers from the northern part (3a) to the southern part (3b).

- 4, Central-France, including the upper stream and rhithral of the Sioule river basin located in the volcanic region of Auvergne (4a); the upper stream of both Allier river and Loire river basin and surrounding piedmont and lowland wetland areas below $1000 \mathrm{~m}(4 \mathrm{~b})$.

- 5, Central-East France, including the upper stream of the Rhone river basin (5a) and the Alpes (especially located in high and middle mountain areas, 5b).

- 6, 7 and 8, French part of the Pyrenees and PrePyrenees, including Western-Pyrenees (6), Central-Pyrenees (7) and Eastern-Pyrenees (8). Pyrenees consist of both mountain and high mountain rivers $(6 \mathrm{a}, 7 \mathrm{a}, 8 \mathrm{a})$, Pre-Pyrenees consist only of piedmont and mountain rivers $(6 \mathrm{~b}, 7 \mathrm{~b}$, $8 b)$.

- 9, South-Central France, including both the inland rivers of the northern part (9a) and the coastal Mediterranean rivers of the southern part (9b). Nevertheless, with respect to chironomid fauna, three geographical zones of biogeographical significance have been identified in the Mediterranean region between the Spanish and the Italian borders (Moubayed et al. 2000).

- 10, South-East France, including the Var and Maritime Alp departments.

Sampling methods mainly used were: Surber net for benthos; Brundin drift net for pharates, pupae and pupal exuviae; Troubleau net for individuals floating on the surface of the water; sweep net for adults.

\section{List of species}

In total, material of 83 chironomid taxa was collected throughout the ten biogeographical areas in Continental France since 1980 (Table 1). Among these taxa there were 8 Tanypodinae, 5 Diamesinae, 35 Orthocladiinae and 35 Chironominae (14 Chironomini and 21 Tanytarsini). Based on recent published data on French chironomid communities (Serra-Tosio and

Table 1. List and geographical distribution of species. * = new record for France; $* *=$ undescribed species; $\mathrm{P}=$ present; $\mathrm{Im}=$ imago; $\mathrm{N}=$ nymph or pharate; $\mathrm{Pe}=$ pupal exuviae; $\mathrm{L}=$ larva

\begin{tabular}{|c|c|c|c|}
\hline List of species & Record & Stage & Distribution \\
\hline \multicolumn{4}{|l|}{ Tanypodinae ( 8 species $)$} \\
\hline Arctopelopia barbitarsis (Zetterstedt) & $\mathrm{P}$ & $\mathrm{Pe}$ & $9 \mathrm{~b}$ \\
\hline Arctopelopia griseipennis (van der Wulp) & $\mathrm{P}$ & $\mathrm{Pe}$ & $7 b, 8 b, 9 b$ \\
\hline Arctopelopia sp.1 & $* *$ & $\mathrm{Pe}$ & $7 \mathrm{~b}, 9 \mathrm{a}$ \\
\hline Conchapelopia hittmairorum Michiels \& Spies & $\mathrm{P}$ & $\mathrm{Pe}$ & $2,5 \mathrm{a}, 8 \mathrm{~b}, 9,10$ \\
\hline Procladius crassinervis (Zetterstedt) & $\mathrm{P}$ & $\mathrm{N}, \mathrm{Pe}$ & $1 b, 2$ \\
\hline Procladius lugens Kieffer & $*$ & $\mathrm{Im}, \mathrm{N}, \mathrm{Pe}$ & $2,5,9$ \\
\hline Procladius rufovittatus van der Wulp & $*$ & $\mathrm{Pe}$ & $2,8 \mathrm{a}, 8 \mathrm{~b}, 9$ \\
\hline Procladius sp.1 (nr Procladius sp, from Norway) & $* *$ & $\mathrm{Pe}$ & $8 \mathrm{a}$ \\
\hline \multicolumn{4}{|l|}{ Diamesinae ( 5 species $)$} \\
\hline Boreoheptagyia rugosa Saunders & $\mathrm{P}$ & $\mathrm{Im}, \mathrm{Pe}$ & $8 b, 10$ \\
\hline Boreoheptagyia sp.1 (near B. rotunda Serra-Tosio) & $* *$ & $\operatorname{Im}$ & 10 \\
\hline Diamesa thomasi Serra-Tosio & $\mathrm{P}$ & $\mathrm{Im}, \mathrm{N}, \mathrm{Pe}, \mathrm{L}$ & $7 \mathrm{a}, 8 \mathrm{a}$ \\
\hline Diamesa veletensis Serra-Tosio & * & $\mathrm{Im}, \mathrm{N}, \mathrm{Pe}, \mathrm{L}$ & $8 \mathrm{a}$ \\
\hline Potthastia sp.1 & $* *$ & $\mathrm{Pe}$ & $4 \mathrm{~b}$ \\
\hline \multicolumn{4}{|l|}{ Orthocladiinae (35 species) } \\
\hline Brillia pudorosa Cobo, Gonzales \& Vieira-Lanero & * & $\mathrm{Im}, \mathrm{N}, \mathrm{Pe}$ & $3 b$ \\
\hline Bryophaenocladius scanicus Brundin & $*$ & Im & $4,8 b, 9$ \\
\hline Bryophaenocladius sp.1 & $* *$ & Im & $9 b$ \\
\hline Corynoneura gratias Schlee & $\mathrm{P}$ & $\mathrm{N}, \mathrm{Pe}$ & $1 \mathrm{a}, 3 \mathrm{a}, 3 \mathrm{~b}, 8 \mathrm{a}, 8 \mathrm{~b}$ \\
\hline Cricotopus algarum (Kieffer) & $\mathrm{P}$ & $\mathrm{Im}, \mathrm{N}, \mathrm{Pe}$ & $1 \mathrm{a}, 1 \mathrm{~b}, 2,3$ \\
\hline Cricotopus caducus Hirvenoja & $\mathrm{P}$ & $\mathrm{Im}, \mathrm{N}, \mathrm{Pe}$ & $1 a, 3 a, 3 b, 9 b$ \\
\hline
\end{tabular}




\begin{tabular}{|c|c|c|c|}
\hline List of species & Record & Stage & Distribution \\
\hline Cricotopus sp.1 (nr C. levantinus Moubayed \& Hirvenoja) & ** & $\mathrm{N}, \mathrm{Pe}$ & $9 b, 10$ \\
\hline Eukiefferiella bedmari Vilchez-Quero \& Laville & * & $\mathrm{Im}, \mathrm{Pe}$ & $1 a, 3 a, 3 b$ \\
\hline Eukiefferiella brehmi Gowin & * & $\mathrm{Pe}$ & $8 \mathrm{a}, 8 \mathrm{~b}, 9 \mathrm{a}, 10$ \\
\hline Euryhapsis fuscipropes Sæther \& Wang & * & $\mathrm{N}, \mathrm{Pe}$ & $6 b, 9 b$ \\
\hline Georthocladius sp.1 & ** & $\mathrm{Pe}$ & $8 \mathrm{a}$ \\
\hline Heterotrissocladius grimshawi Edwards & * & $\mathrm{N}, \mathrm{Pe}$ & $2,5 \mathrm{a}, 10$ \\
\hline Heterotrissocladius sp.1 & ** & $\mathrm{Pe}$ & $9 \mathrm{~b}$ \\
\hline Krenosmittia hispanica Wüelker & * & $\mathrm{Im}, \mathrm{N}, \mathrm{Pe}$ & $8 \mathrm{a}, 8 \mathrm{~b}$ \\
\hline Limnophyes bidumus Sæther & * & $\mathrm{Im}, \mathrm{N}, \mathrm{Pe}$ & $5 \mathrm{~b}, 8 \mathrm{a}, 9,10$ \\
\hline Limnophyes gelasinus Sæther & * & $\mathrm{Im}, \mathrm{N}, \mathrm{Pe}$ & $9 b, 10$ \\
\hline Limnophyes spinigus Sæther & * & $\mathrm{Im}, \mathrm{Pe}$ & $7 \mathrm{a}, 8 \mathrm{a}$ \\
\hline Orthocladius holsatus Goetghebuer & $*$ & $\mathrm{Pe}$ & $7 \mathrm{~b}, 8 \mathrm{~b}$ \\
\hline Parachaetocladius sp.1 & ** & $\operatorname{Im}$ & $8 \mathrm{a}$ \\
\hline Parakiefferiella sp.1 & ** & $\mathrm{Im}, \mathrm{N}, \mathrm{Pe}$ & $9 \mathrm{a}$ \\
\hline Paralimnophyes longiseta Thienemann & $\mathrm{P}$ & $\mathrm{Im}, \mathrm{Pe}$ & $2,3,4 b, 5 a$ \\
\hline Paraphaenocladius intercidens Brundin & * & $\mathrm{Pe}$ & $8 \mathrm{a}$ \\
\hline Paratrichocladius lanzavecchiae Rossaro & * & $\mathrm{Im}, \mathrm{N}, \mathrm{Pe}$ & $9 a, 9 b, 8 b, 10$ \\
\hline Paratrichocladius veronicae Rossaro & * & $\operatorname{Im}$ & $8 b, 9 b$ \\
\hline Pseudorthocladius sp.1 & ** & $\mathrm{Pe}$ & $8 \mathrm{a}, 8 \mathrm{~b}$ \\
\hline Pseudosmittia angusta (Edwards) & $\mathrm{P}$ & Im & $1 \mathrm{a}, 1 \mathrm{~b}, 2,3 \mathrm{a}, 5 \mathrm{a}$ \\
\hline Smittia aquatilis Goetghebuer & * & $\mathrm{Im}$ & $1 \mathrm{~b}, 2$ \\
\hline Smittia betuletorum Edwards & * & Im & 2 \\
\hline Smittia foliacea (Kieffer) & $\mathrm{P}$ & $\mathrm{Im}$ & $1 \mathrm{a}, 2,3 \mathrm{a}, 5,9,10$ \\
\hline Smittia longitibia Goetghebuer & * & Im & $3 \mathrm{~b}, 6 \mathrm{~b}$ \\
\hline Smittia paranudipennis Brundin & * & Im & $7 \mathrm{a}, 8 \mathrm{a}$ \\
\hline Smittia reissi Rossaro \& Orendt & * & Im & $9 \mathrm{~b}$ \\
\hline Smittia scutellosaetosa Caspers & $\mathrm{P}$ & $\operatorname{Im}$ & $1,2,8 b, 9 b$ \\
\hline Smittia sp.1 & $* *$ & Im & $1 \mathrm{~b}, 2$ \\
\hline Thienemannia libanica Laville \& Moubayed & $\mathrm{P}$ & $\mathrm{Pe}$ & $5 b, 10$ \\
\hline \multirow{2}{*}{\multicolumn{4}{|c|}{$\begin{array}{l}\text { Chironominae ( } 35 \text { species) } \\
\text { Chironomini ( } 14 \text { species) }\end{array}$}} \\
\hline & & & \\
\hline Chironomus sp.1 & ** & $\mathrm{Im}, \mathrm{N}, \mathrm{Pe}, \mathrm{L}$ & $1 b, 2$ \\
\hline Cryptotendipes nigronitens (Edwards) & * & $\operatorname{Im}, \mathrm{N}, \mathrm{Pe}$ & $2,3 \mathrm{~b}, 9 \mathrm{a}$ \\
\hline Cryptotendipes usmaensis (Pagast) & $\mathrm{P}$ & $\mathrm{N}, \mathrm{Pe}$ & $1 b, 2,4 b, 9 b$ \\
\hline Dicrotendipes pallidicornis Goetghebuer & * & $\mathrm{Im}, \mathrm{Pe}$ & $1 b, 2$ \\
\hline Glyptotendipes signatus Kieffer & $\mathrm{P}$ & $\mathrm{Im}, \mathrm{N}, \mathrm{Pe}$ & $1 b, 2,5 \mathrm{a}$ \\
\hline Microchironomus deribae (Freeman) & $\mathrm{P}$ & $\mathrm{Im}, \mathrm{N}, \mathrm{Pe}$ & $1 b, 2,3$ \\
\hline Parachironomus digitalis Edwards & * & $\mathrm{Im}, \mathrm{N}, \mathrm{Pe}$ & $9 \mathrm{a}, 9 \mathrm{~b}$ \\
\hline Parachironomus sp.1 & ** & $\mathrm{Im}, \mathrm{N}, \mathrm{Pe}, \mathrm{L}$ & $1 \mathrm{~b}, 2$ \\
\hline Polypedilum bicrenatum Kieffer & $\mathrm{P}$ & $\mathrm{Im}, \mathrm{N}, \mathrm{Pe}$ & $3 a, 3 b, 9 b, 10$ \\
\hline Polypedilum tetracrenatum Hirvenoja & * & $\mathrm{Im}, \mathrm{N}, \mathrm{Pe}$ & $1 b, 2$ \\
\hline Polypedilum (Cerobregma) lotensis Moubayed-Breil & $\mathrm{P}$ & $\mathrm{Im}, \mathrm{N}, \mathrm{Pe}$ & $9 \mathrm{a}$ \\
\hline Polypedilum (C.) scetheri Moubayed-Breil & $\mathrm{P}$ & $\mathrm{Im}, \mathrm{N}, \mathrm{Pe}$ & $4 a, 4 b, 9 a$ \\
\hline Polypedilum (Tripodura) sp.1 & ** & $\mathrm{Pe}$ & $8 \mathrm{~b}, 9 \mathrm{~b}$ \\
\hline Sergentia coracina (Zetterstedt) & * & $\mathrm{Im}, \mathrm{Pe}$ & $1 b, 2,4 b, 9$ \\
\hline \multicolumn{4}{|l|}{ Tanytarsini ( 21 species $)$} \\
\hline Cladotanytarsus conversus Johannsen & $\mathrm{P}$ & $\mathrm{Im}, \mathrm{N}, \mathrm{Pe}, \mathrm{L}$ & $1 b, 2$ \\
\hline Cladotanytarsus nigrovitattus Goetghebuer & $\mathrm{P}$ & $\mathrm{Im}, \mathrm{Pe}$ & $1 b, 2,8 \mathrm{a}, 8 \mathrm{~b}$ \\
\hline Constempellina brevicosta (Edwards) & * & $\mathrm{Im}, \mathrm{N}, \mathrm{Pe}$ & $5 \mathrm{~b}, 9 \mathrm{a}$ \\
\hline Constempellina sp.1 & ** & $\mathrm{Pe}$ & $1 b, 2$ \\
\hline Micropsectra aristata Pinder & * & $\mathrm{Im}, \mathrm{N}, \mathrm{Pe}$ & $1 \mathrm{a}, 3 \mathrm{a}, 3 \mathrm{~b}, 8 \mathrm{~b}$ \\
\hline Micropsectra bavarica Stur \& Ekrem & * & $\mathrm{Im}, \mathrm{N}, \mathrm{Pe}$ & $4 a, 4 b, 5,8,9,10$ \\
\hline Micropsectra schrankelae Stur \& Ekrem & * & $\mathrm{Im}, \mathrm{N}, \mathrm{Pe}$ & $1,2,3,4,5 \mathrm{a}, 8 \mathrm{~b}, 9,10$ \\
\hline Micropsectra sofiae Stur \& Ekrem & * & $\mathrm{Im}, \mathrm{N}, \mathrm{Pe}$ & $2,4,5 \mathrm{a}, 8 \mathrm{a}, 8 \mathrm{~b}, 9,10$ \\
\hline Micropsectra sp.1 & ** & $\mathrm{Im}, \mathrm{N}, \mathrm{Pe}, \mathrm{L}$ & $8 \mathrm{a}$ \\
\hline Neozavrelia cuneipennis (Edwards) & * & $\mathrm{Im}, \mathrm{N}, \mathrm{Pe}$ & $1 \mathrm{a}, 2,8 \mathrm{a}, 9 \mathrm{a}$ \\
\hline Neozavrelia luteola Goetghebuer & * & Im,N,Pe & $9 a, 9 b$ \\
\hline
\end{tabular}




\begin{tabular}{lccc}
\hline \multicolumn{1}{c}{ List of species } & Record & Stage & Distribution \\
\hline Parapsectra uliginosa Reiss & $*$ & $\mathrm{Im}, \mathrm{N}, \mathrm{Pe}$ & $8 \mathrm{a}$ \\
Rheotanytarsus sp.1 & $* *$ & $\mathrm{Im}, \mathrm{N}, \mathrm{Pe}, \mathrm{L}$ & $8 \mathrm{a}, 8 \mathrm{~b}$ \\
Stempellina almi Brundin & $\mathrm{P}$ & $\mathrm{Im}, \mathrm{N}, \mathrm{Pe}, \mathrm{L}$ & $1 \mathrm{~b}, 2,5 \mathrm{~b}, 9 \mathrm{~b}, 10$ \\
Stempellina subglabripennis (Brundin) & $\mathrm{P}$ & $\mathrm{N}, \mathrm{Pe}$ & $9 \mathrm{a}, 9 \mathrm{~b}, 10$ \\
Stempellinella brevis (Edwards) & $\mathrm{P}$ & $\mathrm{Im}, \mathrm{N}, \mathrm{Pe}, \mathrm{L}$ & $2,3,4,5 \mathrm{a}, 8 \mathrm{~b}, 9,10$ \\
Stempellinella reissi Casas \& Vilchez-Quero & $\mathrm{P}$ & $\mathrm{Im}, \mathrm{N}, \mathrm{Pe}, \mathrm{L}$ & $8 \mathrm{a}, 8 \mathrm{~b}, 4 \mathrm{~b}, 9 \mathrm{a}$ \\
Tanytarsus longitarsis Kieffer, & $*$ & $\mathrm{~N}, \mathrm{Pe}$ & $1 \mathrm{~b}, 2$ \\
Tanytarsus multipunctatus Brundin & $*$ & $\mathrm{Im}, \mathrm{N}, \mathrm{Pe}$ & $1 \mathrm{~b}, 2$ \\
Virgatanytarsus sp.1 & $* *$ & $\mathrm{Pe}$ & $8 \mathrm{~b}, 9 \mathrm{a}, 9 \mathrm{~b}$ \\
Virgatanytarsus sp.2 & $* *$ & $\mathrm{Pe}$ & $1 \mathrm{~b}, 2$ \\
\hline
\end{tabular}

Laville 1991, Laville and Serra-Tosio 1996, Moubayed et al. 2000, Delettre 2001, Sæther and Spies 2004; Garcia and Laville 2000), 37 species are new records for France $(*)$ and 20 species belong to new undescribed species $(* *)$. The remaining species $(\mathrm{P})$ are considered to be new records for some regions or subregions of France. Thus, including the 37 new records which represent $5 \%$ of the French chironomid fauna, 718 chironomid species are now known from France. Of the 1237 European species listed in the last version of Fauna Europaea for Chironomidae by Sæther and Spies (2004), 58\% are recorded from France. In the current study, the highest diversity (37 and 34 species) was encountered in two areas located in southern France: south-central France (region 9, 45.6\%), eastern Pyrenees (subregion 8, 42\%).

\section{Distribution of some species and remarks}

- Procladius sp.1. Pupal material of Procladius sp. 1 is collected in a high altitude lake in Eastern Pyrenees. It fits the description of Procladius sp reported from Norway by Fittkau and Murray (1985: 96, Fig. 5.31, C). This undescribed species can be easily recognized on the basis of the following thoracic horn characters: elliptic plastron; rim weakly represented, almost absent; respiratory atrium oval, elongated and larger at apex.

- Procladius crassinervis (Zetterstedt) was first reported by Serra-Tosio and Laville (1991) as a probable species from South Eastern France. The present record is based on mature male adults, pharates and pupal exuviae collected in lakes, ponds and large reservoirs located in northern areas at low altitude (1b, 2).

- Boreoheptagyia sp.1. Only one male adult was collected in a spring located in south eastern France (region 10). The species is morphologically similar to Boreoheptagyia rotunda Serra-Tosio but can be distinguished from this species by the following combination of characters: antenna $715 \mu \mathrm{m}$ long; $\mathrm{AR}=0.67$; last flagellomere $185 \mu \mathrm{m}$ long, elongated, longer than preceding 4 segments combined; presence of anal point on tergite IX; absence of notch on gonostylus.

- Diamesa thomasi Serra-Tosio. In France, D. thomasi has been recorded only from the two type localities located in the Central Pyrenees (7a, 4 adults) by Serra-Tosio (1970). I have found it in the Eastern Pyrenees (subregion 8a) where very large populations (adults, pharates, pupae and larvae) were collected, inhabiting high altitude peat pits located at $2250 \mathrm{~m}$; examples of associated species are $D$. aberrata Lundeberg, $D$. bohemani Goetghebuer, D. bertrami Edwards, D. veletensis Serra-Tosio, D. zernyi Edwards, Pseudodiamesa nivosa (Goetghebuer), $P$. branickii (Nowicki), Chaetocladius suecicus (Kieffer), Krenoposectra nohedensis Moubayed and Langton, Micropsectra auvergnensis Reiss.

- Cricotopus sp.1 is morphologically similar to C. levantinus Moubayed and Hirvenoja known from the lotic part of the Orontes River in Lebanon. Recently this species has been recorded from South-West Europe including France, Spain, Corsica (Fauna Europaea, Sæther and Spies 2004). Associated material including male adults, pharates, pupae and pupal exuviae of Cricotopus sp.1 was recently reported also from Algeria by Moubayed-Breil and Lounaci (2007) and shows that it belongs to a new species or new subspecies different from C. levantinus: the male imago lacks a notch on the gonocoxite lobe, the distribution of anterior armament on tergites III-VI of the pupal exuviae are not crescent-like and the size of spines on the pupal abdominal tergites are stronger in levantinus. Comparison of 
material from both Algeria and France with type material from Lebanon allowed us to consider that Cricotopus sp.1 from France, belongs to the same new species or subspecies as reported from Algeria. In addition, despite several lists of species reported from intense investigations in Syrian and Turkish territories along the extended basin of the Orontes River (Reiss 1985, 1986; Caspers and Reiss 1989) populations of $C$. levantinus are not recorded from these two neighboring countries.

- Eukiefferiella bedmari Vilchez-Quero \& Laville is reported as a circum-mediterrenean element well known from both AtlantoMediterranean (Spain, Morocco) and PontoMediterranean (Greece, Lebanon, Turkey) regions (Vilchez-Quero and Laville 1987; Laville and Reiss 1992). Eukiefferiella bedmari shows an unexpectedly large geographical distribution northward along both the South-West and Central-West Atlantic coastal streams (3a, 3b), and even reaches the Channel coastal streams (1a). However, despite thorough investigations in Southern France including Mediterranean coastal streams and rivers, this is the first record for this species in France. The material examined consists of a few pupal exuviae collected in some small Atlantic coastal rivers located in subregions 1a, 3a and $3 b$.

- Limnophyes gelasinus Sæther has been known only from 1 single male adult from Korea (Sæther 1990). Here, L. gelasinus is for the first time recorded from the European continent (France), but it was also recently recorded from the North African region (Algeria) by Moubayed and Lounaci (2007). The material consists of a few male pharates and pupal exuviae, and the species seems to be well represented in south eastern France (region10) and the Aissi oued basin in Algeria.

- Paralimnophyes longiseta Thienemann has been exclusively encountered in both central and northern parts of Continental France (Serra-Tosio and Laville 1991, Delettre 2001). Male adults of $P$. longiseta, are rather well represented in wetland areas near marshes and ponds located eastward and westward of Central-France.

- Pseudosmittia angusta (Edwards), Smittia foliacea (Kieffer) and S. contingens (Walker) were first reported from France by Delettre (2001), but was overlooked in Fauna
Europaea. Only male imagines of $P$. angusta and $S$. foliacea were found in this study, and were collected along wetland and river basins in both the western and the eastern part of France: Atlantic and Channel coastal streams in the west (1a, 3a) and inland rivers in the east (5). In addition, only a few populations of $S$. foliacea are recorded from wetland areas located in the Mediterranean region (9a, 9b, 10).

- Micropsectra schrankelae Stur and Ekrem and $M$. sofiae Stur and Ekrem were recently described from Europe (Stur and Ekrem 2006). The identification of these two species in the male adult or pupal stage must be done with care as they are morphologically very similar to $M$. atrofasciata. I have recorded these two species from many regions throughout France, and will expect to see more records throughout the Holarctic region as the species' descriptions become more well known. Undoubtedly, many specimens previously believed to be $M$. atrofasciata probably are different species in the atrofasciata group and $M$. atrofasciata might be less widespread than it has been regarded in previous literature.

- $\quad$ Stempellinella reissi Casas \& Vilchez-Quero was until recently only known from its type locality in Sierra Nevada, Andalucia, Spain (Casas and Vilchez-Quero 1991). Material collected by me in the French Eastern Pyrenees was included in a recently published revision on Stempellinella (Ekrem 2007). Large populations of $S$. reissi have been captured from middle and high altitude springs and streams located in Eastern Pyrenees (8a) and Central France (region 4b). Larvae of $S$. reissi inhabit sandy and gravely habitats of cold waters near springs, peat pits and streams located at variable altitudes. Dense populations appear to be more common in streams located in high altitude areas.

\section{Acknowledgements}

Thanks are due to my colleague Torbjørn Ekrem (Trondheim, Norway) for helpful comments on the manuscript.

\section{References}

Casas, J. J. and Vilchez-Quero, A. 1991. Stempellinella reissi sp. n. (Diptera: 
Chironomidae) from Sierra Nevada (Southern Spain). Aquatic Insects, 13 (2): 115-121.

Caspers, N. and Reiss, F. 1989. Die Chironomidae der Turkei. Teil I: Podonominae, Diamesinae, Prodiamesinae, Orthocladiinae (Diptera, Nematocera, Chironomidae). Entomofauna, Zeitschrift Für Entomologie, 10 (8/1):105-160.

Delettre, Y. 2001. An annotated checklist of Chironomidae (Diptera) trapped in Brittany (France) since 1975. Annales de Limnologie, 37 (2) 143-149.

Ekrem, T. 2006. A redescription of Neozavrelia cuneipennis (Edwards) comb. nov., with a checklist of Neozavrelia species of the world (Diptera, Chironomidae). Zootaxa 1153: 116.

Ekrem, T. 2007. A taxonomic revision of the genus Stempellinella (Diptera, Chironomidae). Journal of Natural History, 41 (21-24): 13671465.

Fittkau, E. and Murray, D. A.1985. The pupae of Tanypodinae (Diptera: Chironomidae) of the Holarctic region-Keys and diagnoses. Entomologica Scandinavica, Supplement, 28: 31-113.

Garcia, X. F. and Laville, H. 2000. First inventory and faunistic particularities of the chironomid population from a $6^{\text {th }}$ order section of the sandy River Loire (France). Archiv für Hydrobiologie, 147 (4): 465-484.

Kyerematen, R. A. and Sæther, O. A. 2000. A review of Afrotropical Rheotanytarsus Thienemann et Bause, 1913 (Diptera: Chironomidae). Tijdschrift voor Entomologie 143: 27-69.

Langton, P. H. 1991. A key to pupal exuviae of the west Palaearctic Chironomidae. Privately published: Huntingdon, PE 17 1YH, England, 386 pp.

Langton, P. H. and Visser, H. 2003. Chironomidae exuviae. A key to pupal exuviae of the west Palaearctic region. Amsterdam: Biodiversity Center of ETI.

Laville, H. and Reiss, F. 1992. The Chironomid fauna of the Mediterranean region reviewed. Netherlands Journal of Aquatic Ecology, 26 (2-4): 239-245.

Laville, H. and Serra-Tosio, B. 1996. Additions et corrections à l'inventaire des Chironomidae (Diptera) de France depuis 1990. Annales de Limnologie, 32 (2): 115-121.
Michiels, S. and Spies, M. 2002. Description of Conchapelopia hittmairorum, spec. nov., and redefinition of similar western Palaearctic species (Insecta, Diptera, Chironomidae, Tanypodinae). Spixiana, 25 (3): 251-272.

Moubayed, J. and Hirvenoja, M. 1986. Les Chironomidae du Liban. IV. Cricotopus (Cricotopus) levantinus n. sp. (Diptera: Chironomidae, Orthocladiinae). Bulletin de la Société d'Histoires Naturelles de Toulouse, 122: 169-173.

Moubayed, J., Langton, P.H. and Morello, E. 2000. On some chironomid populations from permanent and temporary springs, streams and pools in France: distribution and biogeographical significance. In: Hoffrichter, O. (Ed.). Late $20^{\text {th }}$ century research on Chironomidae: an anthology from the $13^{\text {th }}$ International Symposium on Chironomidae. Shaker Verlag, Aachen: 571-577.

Moubayed-Breil, J. and Lounaci, A. 2007. New records of chironomids (Diptera) for the fauna of Algeria and North Africa. Ephemera, 8, in print.

Reiss, F. 1985. A contribution to the zoogeography of the Turkish Chironomidae (Diptera). Israel Journal of Entomology, 19: 161-170.

Reiss, F. 1986. Ein Beitrag zur Chironomidenfauna Syriens (Diptera, Chironomidae). Entomofauna, Zeitschrift Für Entomologie, 7 (11): 153-166.

Reiss, F. and Säwedal, L. 1981. Keys to males and pupae of the Palaearctic (Excl. Japan) Paratanytarsus Theinemann \& Bause, 1913, n. comb., with descriptions of three new species (Diptera: Chironomidae). Entomologica Scandinavica, Supplement, 15: 73-104.

Sæther, O.A. 1990. A review of the genus Limnophyes Eaton from the Holarctic and Afrotropical regions (Diptera: Chironomidae, Orthocladiinae). Entomologica scandinavica, Supplement, 35: 1-139.

Sæther, O. A. and Wang, X. 1995. Revision of the genus Paraphaenocladius Thienenemann, 1924 of the world (Diptera: Chironomidae, Orthocladiinae). Entomologica scandinavica, Supplement, 48: 3-69.

Sæther, O. A. and Ferrington, L. C. Jr. 2003. Nomenclature notes on some orthoclads (Diptera: Chironomidae). Zootaxa, 322:1-7.

Sæther, O. A. and Spies, M. 2004. Fauna 
Europaea: Chironomidae. In: de jong, M. (ed.) Fauna Europaea-Diptera: Nematocera, Fauna Europaea version 1.1.

Serra-Tosio, B. 1970. Les Diamesa du groupe damphi. Description d'une espèce nouvelle (Diptera, Chironomidae). Travaux du Laboratoire d'Hydrobiologie, Grenoble, 61 : 107-146.

Serra-Tosio, B. 1989. Révision des espèces ouestpaléarctiques et néarctiques de Boreoheptagyia Brundin avec des clés pour les larves, les nymphes et les imagos (Diptera, Chironomidae). Spixiana, 11 (2): 133-173.

Serra-Tosio, B. and Laville, H. 1991. Liste annotée des Diptères Chironomidés de France continentale et de Corse. Annales de Limnologie, 27 (1): 37-74.

Spies, M. and Sæther, O.A. 2004. Notes and recommendations on taxonomy and nomenclature of Chironomidae (Diptera). Zootaxa, 752: 1-90.
Stur, E. and Ekrem, T. 2006. A revision of West Palaearctic species of the Micropsectra atrofasciata species group (Diptera: Chironomidae). Zoological journal of the Linnean Society, 146: 165-225.

Soponis, A. R. 1990. A revision of the Holarctic species of Orthocladius (Euorthocladius) (Diptera: Chironomidae). Spixiana Supplement, 13: 1-68.

Tuiskunen, J. 1986. The Fennoscandian species of Parakiefferiella Thienemann (Diptera, Chironomidae, Orthocladiinae). ). Annales Zoologici Fennici, 23:175-196.

Vårdal, H. Bjørlo, A. and Sæther, O. A. 2002. Afrotropical Polypedilum subgenus Tripodura, with a review of the subgenus (Diptera: Chironomidae). Zoologica Scripta, 1 (4): 331-402.

Vilchez-Quero, A. and Laville, H. 1987. Eukiefferiella bedmari n. sp., nouvelle espèce à répartition méditerranéenne (Diptera, Chironoomidae). Annales de Limnologie, 23 (3): 209-215. 